\section{In vitro models of human cardiac fibrotic tissue on 'bioartificial' scaffolds}

\author{
Alice Zoso, ${ }^{1-3}$ Irene Carmagnola, ${ }^{1-4}$ \\ Gerardina Ruocco, 1,2 \\ Mattia Spedicati,1,2 Valeria Chiono ${ }^{1-4}$ \\ 1Department of Mechanical and \\ Aerospace Engineering, Politecnico di \\ Torino, Turin; ${ }^{2}$ POLITO Biomedlab, \\ Politecnico di Torino, Turin; \\ 3Interuniversity Center for the promo- \\ tion of the $3 R$ s principles in teaching \\ and research; ${ }^{4} \mathrm{CNR}-\mathrm{IPCF}$, National \\ Research Council - Institute for \\ Chemical and Physical Processes, Pisa, \\ Italy
}

\begin{abstract}
Cardiac infarction is a global burden worldwide that leads to fibrotic and not contractile myocardial tissue. In this work, in vitro models of infarcted tissue were developed as tools to test novel therapies for cardiac regeneration in the future. Human cardiac fibroblasts were cultured on scaffolds, with different compositions and architectures, as to mimic structural and chemical features of infarcted cardiac tissue. Early findings from in vitro cell tests were reported, showing an enhancement of cell attachment and proliferation in the case of "bioartificial" scaffolds, i.e. scaffolds based on a synthetic and a bioactive polymer.
\end{abstract}

\section{Introduction}

Heart failure is a global pathological condition affecting approximately 26 million people worldwide. ${ }^{1}$ Myocardial infarc- tion causes the death of billions of cardiomyocytes followed by the progressive formation of a fibrotic scar mainly populated by cardiac fibroblasts. Fibrotic tissue is mechanically stiffer than healthy cardiac tissue and unable to undergo contraction. ${ }^{2}$ In vitro models of infarcted tissue represent a key tool to evaluate new therapies for cardiac regeneration. In this work, a model of fibrotic heart was designed and fabricated by culturing human cardiac fibroblasts (HCFs) on bioartificial scaffolds with different morphology, mimicking structural and chemical features of infarcted cardiac tissue.

\section{Materials and Methods}

Synthetic polymer scaffolds were prepared by different techniques and, then, functionalised with an adhesive protein. HCFs isolated from human ventricle were cultured onto the scaffolds. Their survival, adhesion, proliferation and morphology were studied by biochemical assays and fluorescence microscopy, as a function of scaffold structure and surface composition.

\section{Results}

SEM analysis allowed to demonstrate the correct design of scaffolds. Functionalised scaffolds showed superior cell attachment and proliferation compared to non-functionalized scaffolds.

\section{Conclusions}

Bioartificial scaffolds were able to support the viability and proliferation of HCFs. The study will allow the modelling of different degrees of human cardiac fibrosis by
Correspondence: Valeria Chiono, Department of Mechanical and Aerospace Engineering, Politecnico di Torino, Turin, Italy.

E-mail: valeria.chiono@polito.it

Key words: Biomimetic scaffolds; extracellular matrix; in vitro human cardiac fibrotic tissue model.

Acknowledgements: BIORECAR project has received funding from the European Research Council (ERC) under the European Union's Horizon 2020 research and innovation programme grant agreement No 772168 .

Conference presentation: this paper was presented at the Second Centro 3R Annual Meeting - 3Rs in Italian Universities, 2019, June 20-21, University of Genoa, Italy.

Received for publication: 28 October 2019.

Accepted for publication: 11 November 2019.

This work is licensed under a Creative Commons Attribution NonCommercial 4.0 License (CC BY-NC 4.0).

(C) Copyright: the Author(s), 2019

Licensee PAGEPress, Italy

Biomedical Science and Engineering 2019; 3(s3):122 doi:10.4081/bse.2019.122

specific constructs, which will be useful for the in vitro testing of advanced therapies.

\section{References}

1. Ponikowski P, Anker SD, AlHabib KF, et al. Heart failure: preventing disease and death worldwide. ESC Heart Fail 2014;1:4-25.

2. Porter KE, Turner NA. Cardiac fibroblasts: at the heart of myocardial remodelling. Pharmacol Ther 2009;123:25578. 